\title{
Study on the Curriculum System Reform in of Vehicle Engineering University of Applied Sciences
}

\author{
Tao Zhu ${ }^{1}$, Qinlao Yan ${ }^{1}$, Quanmin $\mathrm{Li}^{1,2}$ \\ ${ }^{1}$ Mechanical and Electrical Engineering College, Guangdong Baiyun University, Guangzhou \\ Guangdong, 510450, China \\ ${ }^{2}$ Guangdong Polytechnic Normal University, Guangzhou Guangdong, 510450, China
}

Keywords:University of applied sciences, Vehicle engineering, Curriculum reform.

\begin{abstract}
The curriculum system reform in vehicle engineering in the University of Applied sciences integrates theory teaching and practice teaching as a whole,changes the traditional mode of theory teaching separating form practice teaching,and highlights application,comprehensive,practical and advanced of the teaching content and teaching methods.Learning professional course in the professional classroom epitomizes the teaching method of the theory and practice(test).Through the teaching practice,produce the cluster effect;promote the basic change of the traditional teaching mode.
\end{abstract}

\section{Basic requirement of teaching method in universities of applied sciences is application ability teaching.}

Teaching methods in China's "application oriented" undergraduate education never get out of the frame of traditional education mode, far away from the requirement of requirements of universities of applied sciences in both "teaching" and "learning", so as to prevent the teaching target fulfillment. "Integrated" application ability teaching "combining theory with practice closely" has become a common feature of world application oriented undergraduate education. Under the macro background of industry transition and upgrading, science and engineering undergraduate talent cultivation should regulate major structure, reform talent cultivation mode, and update contents and methods with the advancement of science and technology, industry development and reform, and national economic development demands ${ }^{[3]}$. Defects of Chinese traditional education and teaching mode are mainly reflected in three aspects:

\section{Harmful for combination of theoretical teaching and practical teaching}

In traditional teaching method, it is a habit learn theoretical knowledge first and then take professional application ability training. In professional theoretical knowledge learning, students can only "mechanical memorize", "have only a hazy notion", without "in-depth understanding" or "drawing inferences" due to lack of perceptual knowledge of profession. When teachers take blackboard-writing teaching in the practical operation process, students may "feel at a loss, abstract, or tedious. In the teaching stage of professional application ability experiment, students may be interested but forget a lot of their professional technical theoretical knowledge, limited to imitative operation training, unable to establish systematic comprehensive application ability under the guidance of correct theories. Separation of theoretical teaching and practical teaching prevents students stimulating their professional interest and mobilizing their learning activity so that the more they learn the more tedious they feel and they gradually lose confidence of major learning which becomes student's burden and seriously prevent teaching quality from improving. The overall target of universities of applied sciences education is to "comprehensive develop, highlight specialty, 
strengthen practice and focus on application", core requirement is to own "applicable basic theory and good mastery of basic skills", which is decided by student's difference and the diversity of society's layered demand for talent ${ }^{[4-5]}$, as well as the fundamental tenet for universities of applied sciences education in different countries.

\section{Harmful for cooperation between each teaching procedures in professional course}

"Finished automobile" is made up by several subsystems. If following traditional education mode by setting each subsystems to different courses for teaching, it will be hard for each courses to be organically connected and hard to coordinate the inherent connection between teaching materials, and the teaching contents cannot be reasonably overall planned. Some knowledge may be mentioned in each subsystem course to cause content repetition, due to discordant sequence of knowledge, comprehensively applied contents may be used before basic knowledge may not be fully mastered. Knowledge learning has obeyed the progressive cognition rules so as to seriously influence teaching quality and efficiency improvement.

\section{Harmful for establishing "three teacher type" teaching team}

Traditional teaching and education mode focuses on professional theoretical knowledge, emphasizes knowledge instruction and infusion, but ignores cultivation of student's practical application ability, so that teachers will have the tendency of emphasizing theory and neglecting practice, harmful to establishing a "three teacher type" teaching team which can instruct students to take scientific research innovation, instruct professional theoretical courses, but can also guide students' practice in accordance with the requirement of universities of applied sciences.

Traditional education and teaching mode has a lot of defects, undoubtedly against the education mode that universities of applied sciences should apply. In applied sciences construction of our school, it is an inevitable trend to reform traditional education and teaching mode.

\section{Vehicle engineering major course system reform mentality in universities of applied sciences}

Vehicle engineering major aims at improving student's professional application ability level, through analyzing automobile talent market demands and vehicle engineering major professional talent cultivation positioning, to establish vehicle engineering major applied talent cultivation system, i.e.: ability-based, with the mentality of "post-ability-course" to set up course system, with "theory practice closely combined" applied ability as teaching mainline, to constantly look for high quality and effective modern teaching method. In professional course teaching mode, try to promote "integrated" teaching mode reform, conduct "project teaching", "typical case study", "task-driven teaching", "on-spot" teaching and "seminar teaching", so as to achieve the "integration of technology knowledge learning with skill training", "integration of theoretical teaching and practical teaching", "integration of learning and working", "integration of learning and doing" [6-7],for the purpose of adapting the vehicle engineering major education and student development demand. "Integrated education mode" has following characteristics:

Practicability. Integration teaching mode is that teachers and students conducts teaching, learning and doing in an integrated professional classroom by combining theory with practice to complete a teaching task, which has changed the traditional way of separating theoretical teaching with practical teaching and highlighted the applicability, comprehensiveness, practicability and advancement of teaching contents and methods. Conducting vehicle engineering major course learning in integrated professional classroom is a concentrated manifestation of theory practice integrated teaching method which can effectively help students master the practical technology of the first line of production and form a coherent, comprehensive and compete knowledge system.

Efficiency and comprehensiveness. Integration teaching mode has achieved five transformation: teaching knowledge transmission to knowledge processing and conversion; teacher from single type to behavior oriented type; students from passively receiving imitation type to positively practice and brain-hand use innovative type; teaching organization form from fixed classroom and group teaching 
to indoors and outdoors professional classroom and internship worship; teaching method from oral teaching blackboard to concreate and on-site teaching. Integration teaching mode reflects the practicableness, openness and practicability of universities of applied sciences education.

Dynamic integration. Integration teaching mode uses multiple theories and practical course contents to combine and form continuous professional knowledge learning and basic application ability training so as to help students master both professional knowledge learning and professional comprehensive application ability can cooperate with each other and improve learning efficiency.

\section{Conception of vehicle engineering major course system reform mode and implementation method in Guangdong Baiyun University}

\section{Guiding ideology of teaching mode reform}

Closely focus on the cultivation target of "applied science university" education, according to the characteristics of automobile market demand for talent, with vehicle engineering major student's basic principle appropriate sufficiency, aiming at improving comprehensive quality and application ability high level, with practicability application ability teaching as the mainline, according to the principle of theory and practice combination, to fully reflect the modern characteristic and occupational character of "applied science university" teaching method.

\section{Target of professional teaching course reform}

Strengthen the research on automobile enterprise, and confirm the major cultivation target according the automobile enterprise post group, establish new course operation system, reform traditional course system and teaching mode, conduct small-class round robin, comprehensively promote "integration" teaching form, reform existing teaching material and teaching method, introduce action oriented teaching method and project teaching method, to cultivate a high quality "three teacher type" teaching group and help students become automobile professional talents with comprehensive quality, adaptive to automobile enterprise development demand, and master some professional basic theories and comprehensive practice ability and sustainable development ability.

\section{Implementation conception of integration teaching mode}

\section{Establish modular course system}

Based on the guiding ideology of working process systematic course development, divide current teaching plan. Based on researches on automobile enterprise, and the automobile composition, confirm automobile engine, chassis, electrical equipment, and automobile maintenance as major learning field; based on the development status of automobile technology, increase engine electrical control, chassis electrical control, typical vehicle maintenance and inspection learning field; based on the development trend of automobile industry and characteristics of demand for talents, open modules for student's choice to really reflect student-centered teaching guiding ideology. Basis for supporting above learning fields such as college English, advanced mathematics (Electrical), foundations of computer application, mechanical drawing and interchangeability technology, basis of mechanical designing, automobile culture, automobile professional English, automotive electrical and electronics, data retrieval to constitute constitution foundation modules.

Couse reform on vehicle engineering major according to above mentality requires to integrate the major learning fields into eight required modules: automobile mechanics 1 (engine module); automobile mechanics 2 (chassis module); automobile electrical equipment; automobile electronic control technology (engine electronic control module); automobile electronic control 2 (chassis electronic control module); automobile maintenance works (automobile maintenance inspection module); automobile fault diagnostics (typical automobile comprehensive fault diagnostic module). Establish automobile integration professional classroom

To better adapt to teaching requirement, and try best to save teaching resources, conduct integration professional classroom construction in the automobile teaching building based on the teaching 
requirement of automobile professional module and according to vehicle engineering major course standard.

New teaching building totally cover $14000 \mathrm{~m}^{2}$; gross area: $6900 \mathrm{~m}^{2}$; number of classrooms:62; number of work station: 1740 people. Establish "theory practice integrated professional classroom, equipped with vehicle engineering major module system supporting teaching tools so as t satisfy the demand of field operation and comprehensive training in practical teaching, and to create good condition for implementing teaching reform.

Teaching arrangement and overall operation

In actual teaching organization process, there is no need to emphasize the priority of learning some course and another. Instead, according to the relevant working process of automobile engineering major, for the convenience of integration teaching, divide vehicle engineering major course to several learning modules based on talent cultivation direction, each module conducting project teaching based on its own characteristics. Major class training teaching should be divided into 25 people per group based on teaching planning arrangement, mainly in the "theory practice integrated teaching mode, to conduct course teaching.

Implementation, evaluation and feedback of module teaching Implementation condition

(1)Teaching materials: learning suit---all teaching materials required for completing each module including module teaching target, learning flow diagram, teacher's guiding materials (teaching material), student's textbooks, equipment, tools, list of auxiliary teaching tools, several learning units, doc and excel for teaching management use---including student registry form, teaching schedule form (teaching plan), student score list, etc.

(2)"Integration" teaching facilities: audio-visual equipment, professional teaching equipment, tools, student use teaching seat, learning material depositary, and working environment equipment, etc.

Implementation process:

(1)Inspect before teaching implementation: teaching materials, facility inspection, instructing teachers inspect relevant equipment technical condition.

(2)Procedures of implementation: arrange students to relevant teaching sites; welcome students to participate in learning, illustrate the teaching objective of this course; introduce teaching site facilities, safety regulation and matters to be noticed; specifically explain "student centered" and "self-regulated learning schedule" method, explain how to learn "learning unit", how to complete "schedule inspection"; implement theory practice integration teaching with behavior oriented teaching method, four-step teaching method preparation (preparation, teacher's demonstration, student imitation, practice), some learning units apply project teaching method to train student's creativity. Students should be guided and instructed by teachers when learning and researching, and encouraged to find problems and propose problems.

(3)Teaching management: pay attention to teaching process management, manage and control the whole process, focus on teaching effect.

Teaching evaluation: vehicle engineering major should establish special evaluation team to evaluate and make quality appraisal on each module learning.

Module assessment method

(1) Score assessment in each item (module) should apply comprehensive vertical evaluation method throughout the whole learning process to promote students to complete learning tasks, each item (module) assessment including six aspects: checking-in 10\%; learning process, learning result presentation 20\%; homework 10\%; practical assessment 30\%; theoretical assessment $30 \%$. Practical teaching and theoretical teaching should account for 5:3. Each item's comprehensive assessment score should be $100 \%$ totally.

(2)Assessment of each item (module) can use written examination, comprehensive ability assessment, oral test and other methods, based on student's afterward development demand, to formulate relevant rating standard, for justice, fairness and equality. 
(3) Comprehensive assessment score of each integrated course should be weighted according to a certain ratio between the course position and weightiness based on the module content, so as to comprehensively figure out student's score in this course.

Integration course reform is a long term. In current stage, only preliminary conceptive discussion has been made. It requires to be summarized and perfected in future teaching practice, and to establish sound teaching materials and evaluation system in accordance with application oriented technology university education.

\section{Reference}

[1] Zeng Xiaobin. School-running orientation of universities of applied sciences and basic framework of transition project in our university, Guangdong Baiyun University, 2013.

[2] Liu Guifu. Studies on basic characteristics of universities of applied sciences, Guangdong Baiyun University,2013.

[3] Wu Aihua. Adapt to time development, promote reform on higher education of science and engineering, Research in Higher Education of Engineering, 2008, (1), 7-11.

[4] Yuan Jianbo. Innovation and practice of independent college applied talent cultivation mode, Research in Higher Education of Engineering, 2011, (2), 118-123.

[5] Liu Xianjun. Innovation education concept promotes talent cultivation mode reform, Chinese Higher Education, 2009, (1), 18-20.

[6] Zeng Xiaobin. School-running orientation of universities of applied sciences and course system construction in our university, Guangdong Baiyun University, 2013.

[7] Liu Guifu. Education and teaching reform in universities of applied sciences,universities of applied sciences, 2013. 